\title{
Inhaled nitric oxide in patients with the acute respiratory distress syndrome secondary to the 2009 influenza A (H1N1) infection in Canada
}

\author{
Duane J. Funk, MD • Anand Kumar, MD
}

Received: 25 April 2012/Accepted: 22 November 2012/Published online: 7 December 2012

(c) Canadian Anesthesiologists' Society 2012

\section{To the Editor,}

In March 2009, an outbreak of severe respiratory illness, later attributed to novel origin swine influenza A virus (H1N1), caused a worldwide pandemic. ${ }^{1}$ Most patients with H1N1 had a self-limited respiratory illness; however, if hospitalization was required, $20-36 \%$ of patients required admission to the intensive care unit (ICU), and $80 \%$ of those patients required invasive mechanical ventilation. The case mortality ranged from $17-40 \%$. In many of these patients, conventional mechanical ventilation strategies were not adequate to reverse their severe oxygenation defects.

Adjunctive therapies in addition to lung protective mechanical ventilation strategies are often trialed in patients with oxygenation failure (defined as $\mathrm{PaO}_{2}<$ $60 \mathrm{mmHg}$ despite $\mathrm{F}_{\mathrm{I}} \mathrm{O}_{2}$ of 1.0 and optimal positive endexpiratory pressure [PEEP]). Inhaled nitric oxide (iNO) is one such therapy that has shown an improvement in oxygenation in patients with acute respiratory distress syndrome (ARDS). ${ }^{2,3}$ In this report, we describe the epidemiologic characteristics, clinical features, treatment, and outcome in the cohort of patients who had ARDS due to H1N1 and were treated with iNO, and we compare their results with those of patients who did not receive iNO.

Following approval by the University of Manitoba Biomedical Research Ethics Board, we conducted a retrospective chart review of all patients who presented with confirmed H1N1 and were treated with iNO in the teaching

Drs Kumar and Funk were responsible for the study design. Dr. Funk collected and analyzed the data, and both authors were responsible for writing and editing the manuscript.

D. J. Funk, MD $(\varangle)$ A. Kumar, MD

University of Manitoba, Winnipeg, MB, Canada

e-mail: funk@cc.umanitoba.ca intensive care units at the University of Manitoba's two adult medical intensive care units. Baseline demographic and clinical data of patients are shown in the Table.

After administration of iNO, there was a significant and sustained improvement in the $\mathrm{PaO}_{2}$ and $\mathrm{PaO}_{2} / \mathrm{F}_{\mathrm{I}} \mathrm{O}_{2}$ ratio at $24 \mathrm{hr}$, and this improvement persisted throughout the study period (seven days).

Three patients in the iNO group eventually required extracorporeal membrane oxygenation due to their profound ARDS. There were two deaths in the iNO group $(n=9) v s$ ten deaths in the control group $(n=94), 22 \%$ and $11 \%$, respectively.

Previous work has shown only a transient improvement in these parameters that, in many cases, did not persist past $24 \mathrm{hr}$. This result is significant as it shows a sustained improvement in oxygenation in these patients with viral pneumonia.

A possible explanation for the sustained improvement in oxygenation is the fact that the ARDS in all our patients was pulmonary in origin, and pulmonary ARDS is considered to behave differently from extrapulmonary ARDS with respect to the effects of ventilation strategy and PEEP levels. ${ }^{4}$ Also, our patients were receiving definitive therapy for their infection (in the form of antiviral medications). It is known that the early introduction of antivirals in this disease decreased the probability of severe morbidity and mortality. ${ }^{5}$

Inhaled nitric oxide did not improve gas exchange enough to allow earlier removal of mechanical ventilation, and there was no difference in mortality in patients who received iNO compared with controls. There have been similar results in other studies that showed no mortality benefit with the use of iNO., ${ }^{2,3}$ In this and other studies, the iNO acts as a bridge while waiting for the positive effects of other therapies. 
Table Baseline and clinical characteristics of patients treated with iNO $v s$ the cohort that did not receive iNO

Data are shown as mean (standard deviation) unless otherwise specified. Oxygenation at $24 \mathrm{hr}$ and day 7 represents the time after iNO administration. *All patients still required mechanical ventilation at day 7. No patient had received ECMO at day 7, and none had died. iNO = inhaled nitric oxide; $\mathrm{PEEP}=$ positive end-expiratory pressure; $\mathrm{ECMO}=$ extracorporeal membrane oxygenation; $\mathrm{ICU}=$ intensive care unit

\begin{tabular}{|c|c|c|c|}
\hline Patient characteristic & Nitric oxide patients & All patients & $P$ value \\
\hline Confirmed cases, $n$ & 9 & 94 & - \\
\hline Age & $24.7(8.8)$ & $37.4(20.8)$ & 0.07 \\
\hline Female sex, $n(\%)$ & $6(66)$ & $61(65)$ & 1.0 \\
\hline Body mass index & $35.3(7.4)$ & $31.4(11.6)$ & 0.33 \\
\hline APACHE II score & $21.9(7.6)$ & $18.4(8.1)$ & 0.23 \\
\hline \multicolumn{4}{|l|}{ Oxygenation at ICU admission } \\
\hline $\mathrm{PaO}_{2}(\mathrm{mmHg})$ & $62.5(10.3)$ & $82.0(25.3)$ & 0.07 \\
\hline $\mathrm{F}_{\mathrm{I}} \mathrm{O}_{2}$ & $0.89(0.10)$ & $0.59(0.21)$ & 0.004 \\
\hline PEEP $\left(\mathrm{cm} \mathrm{H}_{2} 0\right)$ & $12.5(6.8)$ & $9.2(3.8)$ & 0.03 \\
\hline $\mathrm{PaO}_{2} / \mathrm{F}_{\mathrm{I}} \mathrm{O}_{2}$ ratio & $73.0(20.6)$ & $157.8(68.0)$ & 0.006 \\
\hline Oxygenation at $24 \mathrm{hr}(\mathrm{mmHg})$ & $100.6(33.3)$ & $96.6(50.2)$ & 0.61 \\
\hline Oxygenation day $7^{*}$ (mmHg) & $93.6(28.7)$ & $88.7(26.2)$ & 0.18 \\
\hline PEEP day $7^{*}\left(\mathrm{~cm} \mathrm{H}_{2} 0\right)$ & $15.7(4.3)$ & $10.7(3.9)$ & 0.04 \\
\hline Duration of iNO in days, mean (range) & $10.4(2-23)$ & - & - \\
\hline Mortality, $n(\%)$ & $2(22)$ & $10(11.5)$ & 0.32 \\
\hline Patients requiring ECMO, $n$ & 3 & 0 & - \\
\hline Ventilator days & $27.1(21.2)$ & $12.6(12.4)$ & $<0.01$ \\
\hline ICU stay (days) & $30.3(20.0)$ & $13.7(13.5)$ & 0.01 \\
\hline Hospital stay (days) & $33.8(19.5)$ & $22.8(18.7)$ & 0.26 \\
\hline
\end{tabular}

In other studies, an increase in the rate of adverse renal outcomes has been suggested in patients who receive iNO; ${ }^{2,3}$ however, in our study, serum creatinine and rates of renal failure were similar between groups.

Limitations to our study include its retrospective nature, the small sample size, confounding by indication, and the non-standardized indication for iNO therapy. It is also possible that oxygenation would have improved with time despite administration of iNO. Regardless of these limitations, we did show similar physiologic effects of iNO as seen in other studies.

In summary, our study showed a significant and sustained improvement in the $\mathrm{PaO}_{2} / \mathrm{F}_{\mathrm{I}} \mathrm{O}_{2}$ ratio and $\mathrm{PaO}_{2}$ in patients with ARDS due to $\mathrm{H} 1 \mathrm{~N} 1$. This sustained improvement in $\mathrm{PaO}_{2} / \mathrm{F}_{\mathrm{I}} \mathrm{O}_{2}$ ratio and $\mathrm{PaO}_{2}$ has not been seen in studies with a heterogeneous cause of ARDS. Inhaled nitric oxide may be considered in patients with severe hypoxemia when the ARDS is derived from a treatable respiratory origin.

The authors have no financial disclosures. The study was supported by the University of Manitoba Department of Anesthesiology and Perioperative Medicine.
Competing interests None declared.

\section{References}

1. Perez-Padilla $R$, de la Rosa-Zamboni D, Ponce de Leon $S$, et al. Pneumonia and respiratory failure from swine-origin influenza A (H1N1) in Mexico. N Engl J Med 2009; 361: 680-9.

2. Adhikari NK, Burns KE, Friedrich JO, Granton JT, Cook DJ, Meade MO. Effect of nitric oxide on oxygenation and mortality in acute lung injury: systematic review and meta-analysis. BMJ 2007; 334: 779.

3. Afshari A, Brok J, Moller AM, Wetterslev J. Inhaled nitric oxide for acute respiratory distress syndrome (ARDS) and acute lung injury in children and adults. Cochrane Database Syst Rev 2010; (7): CD002787.

4. Rocco PR, Zin WA. Pulmonary and extrapulmonary acute respiratory distress syndrome: are they different? Current Opin Crit Care 2005; 11: 10-7.

5. Louie JK, Acosta M, Jamieson DJ, Honein MA; California Pandemic (H1N1) Working Group. Severe 2009 H1N1 influenza in pregnant and postpartum women in California. N Engl $\mathrm{J}$ Med 2010; 362: 27-35. 